\title{
Thermodynamic Modeling of Surface Tension of Aqueous Electrolyte Solution by Competitive Adsorption Model
}

\author{
Mohamad Javad Kamali, ${ }^{1}$ Zakarya Kamali, ${ }^{2}$ and Gholamhossein Vatankhah ${ }^{1}$ \\ ${ }^{1}$ Department of Chemical Engineering, Islamic Azad University, Bushehr Branch, Bushehr 751961955, Iran \\ ${ }^{2}$ National Iranian Gas Company (NIGC), Fajr-e Jam Gas Company, Bushehr, Iran \\ Correspondence should be addressed to Mohamad Javad Kamali; kamali.mj@gmail.com
}

Received 14 August 2015; Accepted 4 October 2015

Academic Editor: Marc D. Donohue

Copyright (c) 2015 Mohamad Javad Kamali et al. This is an open access article distributed under the Creative Commons Attribution License, which permits unrestricted use, distribution, and reproduction in any medium, provided the original work is properly cited.

\begin{abstract}
Thermodynamic modeling of surface tension of different electrolyte systems in presence of gas phase is studied. Using the solid-liquid equilibrium, Langmuir gas-solid adsorption, and ENRTL activity coefficient model, the surface tension of electrolyte solutions is calculated. The new model has two adjustable parameters which could be determined by fitting the experimental surface tension of binary aqueous electrolyte solution in single temperature. Then the values of surface tension for other temperatures in binary and ternary system of aqueous electrolyte solution are predicted. The average absolute deviations for calculation of surface tension of binary and mixed electrolyte systems by new model are 1.98 and $1.70 \%$, respectively.
\end{abstract}

\section{Introduction}

For studying the aqueous electrolyte solution in porous media, distillation, extraction process, and liquid-liquid dispersion, the calculation of surface tension of aqueous solutions is required [1]. So different equations have been developed to calculate surface tension of mineral salts. Ariyama [2], Lorenz [3], Young and Grinstead [4], and Gleim and Shelomov [5] formulated useful equations as group contribution method for calculation of surface tension of some limited binary electrolyte-water systems. Oka [6] proposed an equation for calculation of surface tension based on the concentration of solution, electronic charge, dielectric constant of water, ionic charge, and Avogadro's constant. Later Hovarth [7] developed this equation by introducing the ionic strength and degree of dissociation into Oka's model [6]. Onsager and Samaras [8] obtained a relation based on the temperature, dielectric constant of water, and concentration of solution for calculation of surface tension of electrolyte solution. Schmutzer [9] considered the osmotic coefficient as an important factor for calculation of surface tension of electrolyte solution. Adding a proportional factor of anion concentration to the surface tension of water, the surface tension of aqueous electrolyte solution was determined by
Abramazon and Gaukhberg [10]. This parameter was considered as a function of the inverse of square of ionic radius and anion charge. Li et al. [1] developed a new model for calculation of surface tension of single and mixed electrolyte solution. In this model, the surface layer is considered as a distinct phase where the electrolytes could be entered into it from other phases. The surface tension was obtained using the proportion of molality of salt in surface layer to liquid bulk phase. While this model had satisfactory results in low concentration of electrolytes, in high concentration the calculated surface tension was not in good agreement with experimental data. Yu et al. [11] combined Li et al. [1] model with modified mean spherical approximation (MSA) as osmotic coefficient model. The results showed that the calculated surface tension in highly concentrated regions was improved. Furthermore, the Langmuir gas-solid adsorption model was used at equilibrium condition for calculation of surface tension of mineral salts by $\mathrm{Li}$ and $\mathrm{Lu}$ [12]. The results indicated the satisfactory agreement with experimental data. Sadeghi et al. [13] used the combination of MSA model [14] with the Ghotbi and Vera [15] and the Mansoori et al. [16] equations of state, for correlation of the surface tension of single aqueous solution. Also the surface tension of different mixed aqueous solutions was predicted by this approach. The 


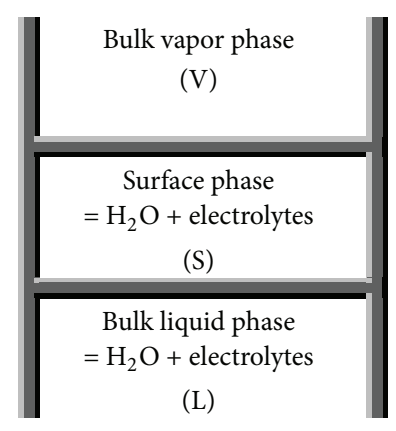

FIGURE 1: Different phases in aqueous electrolyte solution-vapor system [1].

results indicate the satisfactory agreement between calculated and experimental data [13].

In this paper, a new model for calculation of surface tension of the electrolyte systems is developed using the Langmuir adsorption equation and E-NRTL [17] model. The adjustable parameters of this model are obtained by experimental data of surface tension at single temperature. Then the model is verified by prediction of surface tension of 65 binary electrolyte-water systems and 17 ternary electrolyte systems.

\section{Thermodynamic Modeling}

For calculation of surface tension of electrolyte system, the aqueous electrolyte solution-vapor system is supposed as three different phases: bulk vapor phase, surface phase, and bulk liquid phase (Figure 1). The surface phase is considered as distinct layer for adsorption of electrolyte from liquid phase. In this system, the chemical potential of water in liquid bulk phase and surface would be defined as follows [1]:

$$
\begin{aligned}
& \mu_{w}^{L}=\mu_{w}^{L_{0}}+R T \ln a_{w}^{L} \\
& \mu_{w}^{S}=\mu_{w}^{S_{0}}+R T \ln a_{w}^{S}-\bar{A}_{w} \sigma_{\mathrm{sol}},
\end{aligned}
$$

where $\mu, a, \bar{A}$, and $\sigma_{\text {sol }}$ represent the chemical potential, activity, partial molar area, and surface tension of solution. The subscripts $w, L, S, L_{0}$, and $S_{0}$ refer to water, liquid phase, surface phase, reference state of liquid phase, and reference state of surface phase, respectively.

At equilibrium condition, the chemical potential of water in surface and liquid phase is equal. So we have

$$
\mu_{w}^{S_{0}}-\mu_{w}^{L_{0}}+R T \ln a_{w}^{S}-R T \ln a_{w}^{L}=\bar{A}_{w} \sigma_{\text {sol }} .
$$

Rewriting the above equation for pure water, it yields the following equation:

$$
\sigma_{w} A_{w}=\mu_{w}^{S_{0}}-\mu_{w}^{L_{0}} .
$$

It would be worth noting that the activity of pure water is unity and the partial molar area for pure water is equal to the molar area.
Substituting the above equation into (2) results in the following equation:

$$
\sigma_{\text {sol }}=\sigma_{w}+\frac{R T}{A_{w}} \ln \frac{a_{w}^{S}}{a_{w}^{L}} .
$$

It is assumed that in the above equation the partial molar area and molar area of water are equal. The molar area of water is calculated by [18]

$$
\bar{A}_{w}=A_{w}=\left(V_{w}\right)^{2 / 3}\left(N_{A}\right)^{1 / 3},
$$

where $V_{w}$ and $N_{A}$ are molar volume of water and Avogadro number.

Using the osmotic definition $(\phi)$ instead of activity of water, (4) converts to the following equation:

$$
\sigma_{\text {sol }}=\sigma_{w}+\frac{v R T}{55.51 A_{w}}\left(m^{L} \varphi^{L}-m^{S} \varphi^{S}\right),
$$

where $m$ is molality of electrolyte in aqueous solution and $v$ is stoichiometric coefficient. For calculation of the molality of electrolyte in surface phase $\left(\mathrm{m}^{S}\right)$, the fraction of adsorbed electrolyte $(\theta)$ on the interface between vapor and liquid phases could be related to the excess area $(\Gamma)$ as [12]

$$
\theta=\frac{\Gamma}{\Gamma^{0}},
$$

where superscript 0 means saturated condition. On the other hand, the excess area is defined as moles of electrolyte in surface per area of surface [19]. So,

$$
\theta=\frac{n^{S} / A_{s}}{n^{0} / A_{s}}=\frac{n^{S}}{n^{0}}=\frac{m^{S}}{m^{0}},
$$

where $n$ is mole number and superscript $S$ indicates the surface phase. The saturated molality of surface phase is considered as fraction of molality of liquid bulk phase or

$$
m^{0}=K^{0} m^{L}
$$

where $L$ is liquid bulk phase and $K^{0}$ is a constant.

Using the Langmuir gas-solid adsorption [20] and equality of adsorption and desorption rate for an electrolyte in surface phase [21], the adsorbed fraction of electrolyte on the surface phase is obtained as [12]

$$
\theta=\frac{K a}{1+K a} .
$$

Combining (6)-(8), the molality of electrolyte in surface phase would be obtained as

$$
m^{S}=\frac{K^{*} a}{1+K a} m^{L},
$$

where $K^{*}=K^{0} K$.

So, substituting (11) into (6), the surface tension of pure aqueous electrolyte solution is calculated. It is mentioned that the two adjustable parameters $K^{*}$ and $K$ are obtained from 
fitting the experimental surface tension data to the calculated values (see (6)) at single temperature.

For mixed electrolyte solution the surface tension would be calculated by the following equation:

$$
\sigma_{\mathrm{sol}}=\sigma_{w}+\frac{R T}{55.51 A_{w}}\left(\varphi^{L} \sum_{i} v_{i} m_{i}^{L}-\varphi^{S} \sum_{i} v_{i} m_{i}^{S}\right) .
$$

Assuming competitive adsorption between electrolytes in surface phase [12], the molality of surface phase is

$$
m_{i}^{S}=\frac{K_{i}^{*} a_{i}}{1+\sum_{j} K_{j} a_{j}} m_{i}^{L} .
$$

\section{Result and Discussion}

For studying the surface tension of electrolyte solution, 65 binary electrolyte systems and 17 ternary electrolyte systems are selected. The surface tension of these electrolyte solutions is obtained by competitive adsorption model (see (6) or (12)). In this model, for calculation of osmotic and activity coefficients, E-NRTL [17] model is used. Using the regression of model with experimental surface tension of binary electrolyte-water system, the adjustable parameters of competitive adsorption model $\left(K^{*}, K\right)$ are optimized. The objective function is defined as follows:

$$
\mathrm{AAD}=\frac{100}{N_{p}} \sum_{i=1}^{N_{p}} \frac{\left|\sigma_{\mathrm{sol}}^{\mathrm{cal}}-\sigma_{\mathrm{sol}}^{\exp }\right|}{\sigma_{\mathrm{sol}}^{\exp }}
$$

where $\mathrm{AAD}, N_{p}$, and superscripts cal and exp are average absolute deviation, number of data points, and calculated and experimental data of surface tension, respectively. The results for different binary electrolyte system are given in Table 1. So, at single temperature for each salt which is given in Table 1, the surface tension is correlated.

As it is shown in Table 1, when the first adjustable parameter $\left(K^{*}\right)$ tends to zero or small positive value or the second adjustable parameter $(K)$ becomes a large number, the molality of electrolyte system in surface phase is close to zero. Moreover, when $K^{*}$ is lower than unity and $K$ is not moderately large number, the molality of electrolyte in surface phase decreases with respect to the liquid bulk phase. In these cases, which point out to the mineral salts, the rate of adsorption in surface layer would be lower than desorption rate and surface tension of electrolyte solution is increased with respect to the surface tension of water. Strong inorganic acids, organic acetates, and propionates which have high vapor pressure tend to escape from liquid phase to surface phase and consequently the concentration of these components in surface phase would be greater than liquid phase [11]. For these electrolytes, the first adjustable parameter is higher than unity and so the molality of electrolyte in surface phase becomes greater than the liquid bulk phase and consequently the surface tension of aqueous electrolyte solution increases with respect to the liquid bulk phase.

For other temperatures, the value of surface tension of electrolyte aqueous solution is predicted and the results are

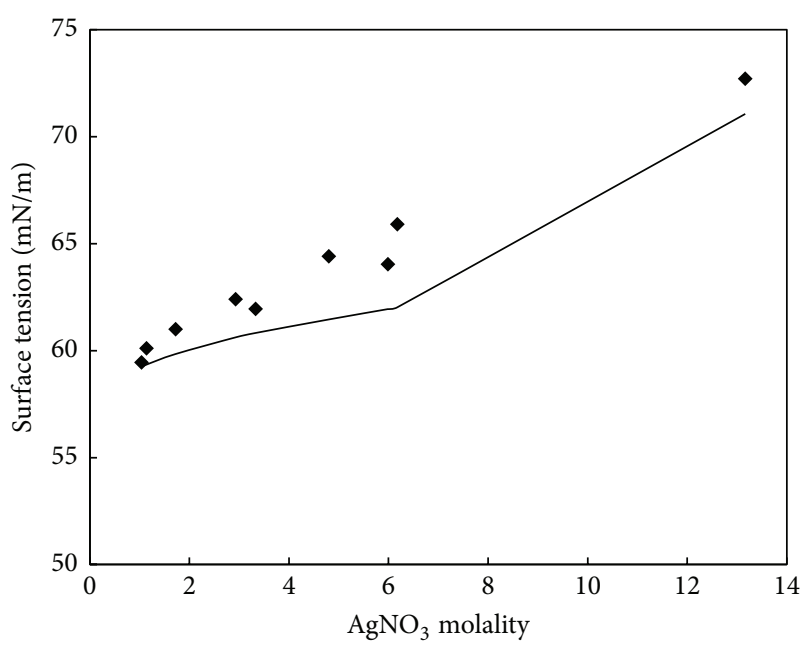

FIgure 2: Prediction of surface tension of $\mathrm{AgNO}_{3}$-water binary system at $283.15 \mathrm{~K}$ using the competitive adsorption model. Experimental data are taken from [10].

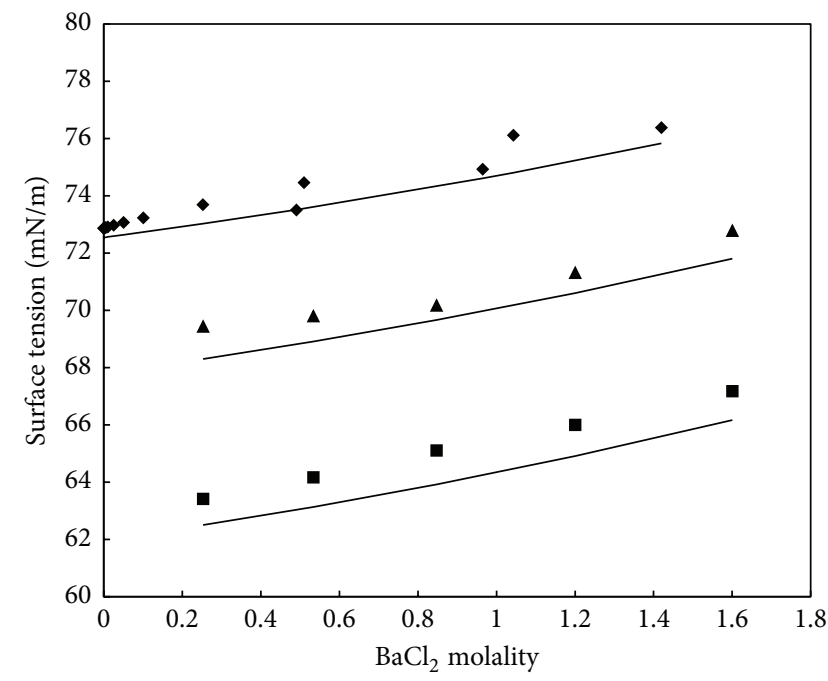

FIGURE 3: Prediction of surface tension of $\mathrm{BaCl}_{2}$-water binary system using the competitive adsorption model. Experimental data are taken from [10] $(\boldsymbol{\nabla}: T=298.15 \mathrm{~K}, \mathbf{\Delta}: T=323.15 \mathrm{~K}$, and $\mathbf{\square}: T=$ $353.15 \mathrm{~K})$.

given in Table 2. Using the competitive adsorption model, the experimental and predicted values of surface tension of aqueous binary electrolyte system are illustrated in Figures $2-8$. These figures indicate the agreement between predicted and experimental values of surface tension values for $\mathrm{AgNO}_{3}$, $\mathrm{BaCl}_{2}, \mathrm{CaCl}_{2}, \mathrm{KBr}, \mathrm{HNO}_{3}, \mathrm{NaCl}$, and $\mathrm{UO}_{2} \mathrm{SO}_{4}$ using E-NRTL [17] model.

For ternary systems, the surface tension of the aqueous solutions is predicted in vast range of temperatures and molalities. The values of AAD for prediction of surface tension of 16 ternary systems by competitive adsorption model are shown in Table 3. The overall AAD for prediction of surface tension of mixed electrolyte solutions is $1.7 \%$. 


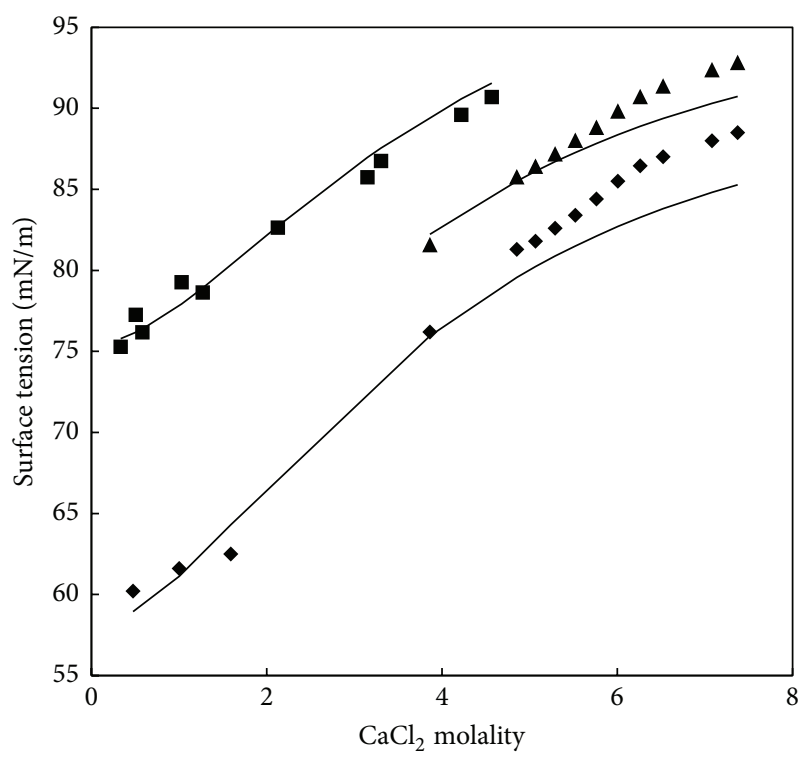

Figure 4: Prediction of surface tension of $\mathrm{CaCl}_{2}$-water binary system using the competitive adsorption model. Experimental data are taken from [10] ( $\mathbf{\square}: T=283.15 \mathrm{~K}, \mathbf{\Delta}: T=333.15 \mathrm{~K}$, and $\downarrow: T=$ $373.15 \mathrm{~K})$.

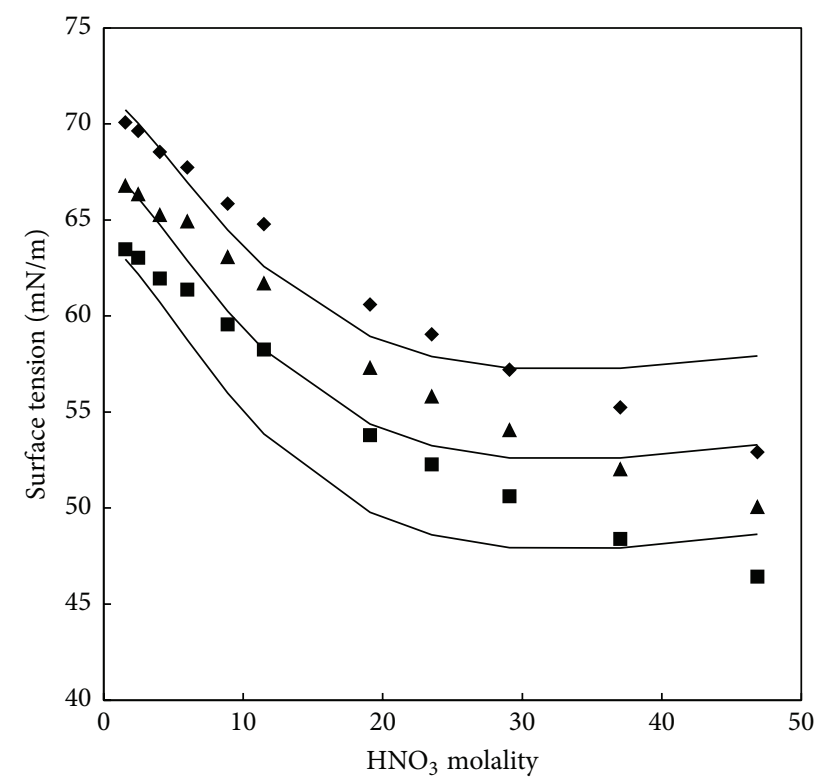

Figure 5: Prediction of surface tension of $\mathrm{HNO}_{3}$-water binary system using the competitive adsorption model. Experimental data are taken from [10] $(\boldsymbol{\vee}: T=303.15 \mathrm{~K}, \mathbf{\Delta}: T=323.15 \mathrm{~K}$, and $\mathbf{\square}: T=$ $343.15 \mathrm{~K})$.

The predicted values of surface tension of $\mathrm{NH}_{4} \mathrm{NO}_{3}$ $\mathrm{KNO}_{3}$-water, $\mathrm{KBr}$ - $\mathrm{KCl}$-water, and $\mathrm{NH}_{4} \mathrm{Cl}$ - $\left(\mathrm{NH}_{4}\right)_{2} \mathrm{SO}_{4}$-water systems by new surface tension model and experimental values are illustrated in Figures 9, 10, and 11, respectively. The agreement between predicted and experimental values in these figures represents the satisfactory results of the competitive adsorption model.

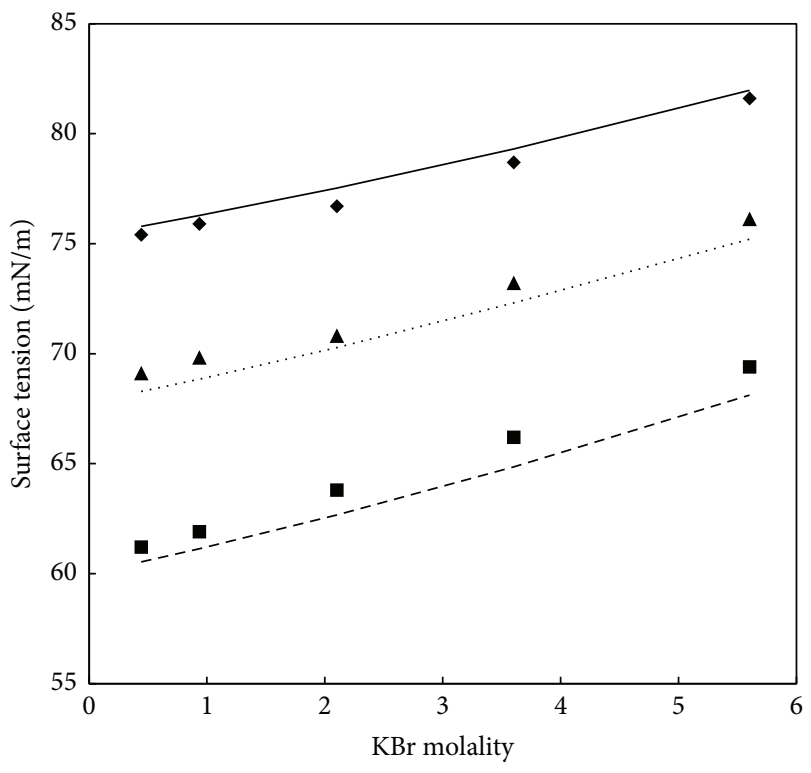

FIGURE 6: Prediction of surface tension of $\mathrm{KBr}$-water binary system using the competitive adsorption model. Experimental data are taken from [10] $(\boldsymbol{\nabla}: T=283.15 \mathrm{~K}, \mathbf{\Delta}: T=323.15 \mathrm{~K}$, and $\mathbf{\mathbf { m }}: T=363.15 \mathrm{~K})$.

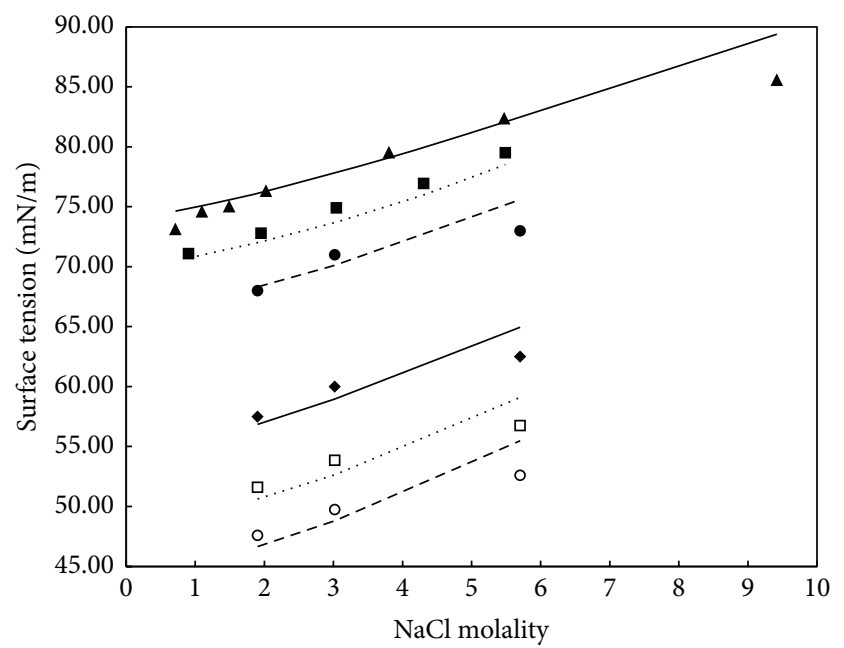

FIGURE 7: Prediction of surface tension of $\mathrm{NaCl}$-water binary system using the competitive adsorption model. Experimental data are taken from [10] $(\mathbf{\Lambda}: T=291.15 \mathrm{~K}, \mathbf{\square}: T=313.15 \mathrm{~K}, \boldsymbol{\bullet}: T=333.15 \mathrm{~K}$, •: $T=393.15 \mathrm{~K}, \square: T=423.15 \mathrm{~K}$, and $\mathrm{O}: T=443.15 \mathrm{~K})$.

\section{Conclusion}

Based on the Gibbs thermodynamic and distinct area for surface phase, a new model for calculation of surface tension of single and mixture electrolyte is developed. The molality in surface phase is calculated using Langmuir gas-solid adsorption theory for electrolytes. The osmotic coefficient model in the competitive adsorption model is E-NRTL model. The adjustable parameters of the model are obtained 


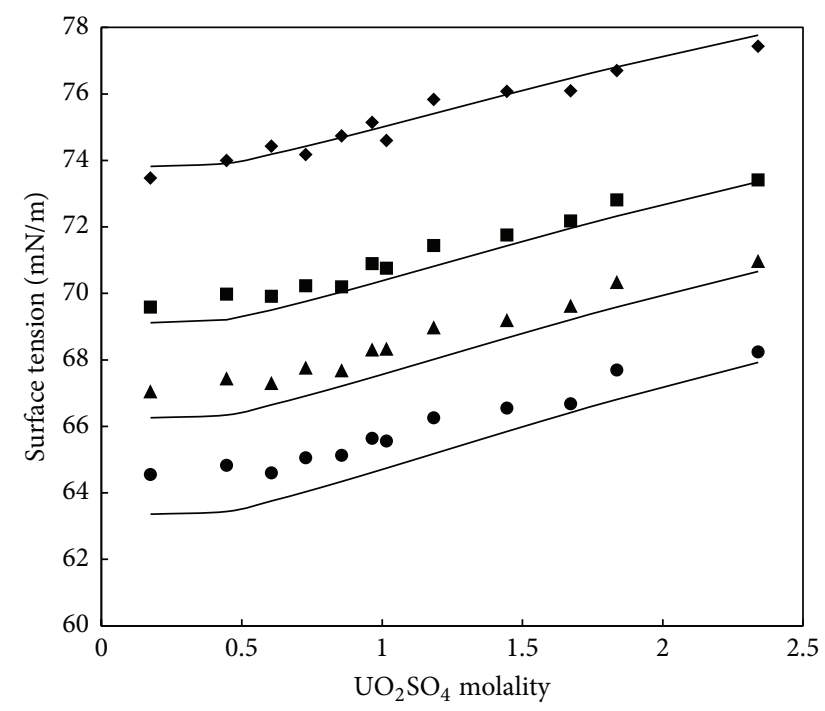

Figure 8: Prediction of surface tension of $\mathrm{UO}_{2} \mathrm{SO}_{4}$-water binary system using the competitive adsorption model. Experimental data are taken from [10] $(\boldsymbol{\bullet}: T=293.15 \mathrm{~K}, \boldsymbol{\square}: T=318.15 \mathrm{~K}, \mathbf{\Lambda}: T=333.15 \mathrm{~K}$, and $\bullet: T=348.15 \mathrm{~K})$.

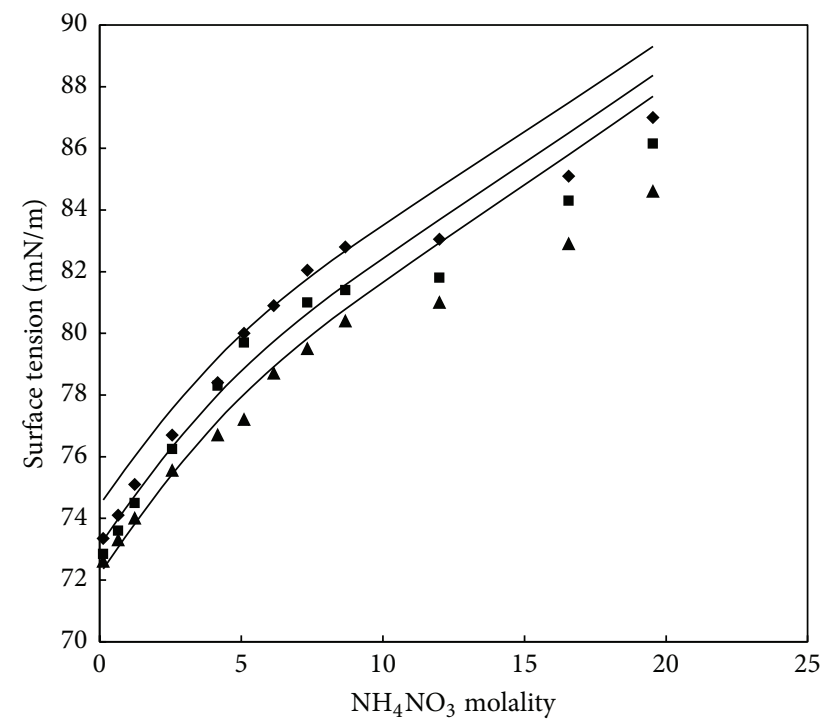

- Exp. data $\left(T=18^{\circ} \mathrm{C}\right) \quad \Delta \quad$ Exp. data $\left(T=30^{\circ} \mathrm{C}\right)$

- Exp. data $\left(T=25^{\circ} \mathrm{C}\right)$ - E-NRTL model

FIgURE 9: Prediction of surface tension of $\mathrm{NH}_{4} \mathrm{NO}_{3}-\mathrm{KNO}_{3}$-water ternary system using the competitive adsorption model with noncompetitive approach $\left(\mathrm{KNO}_{3}\right.$ molality $\left.=0.52\right)$. Experimental data

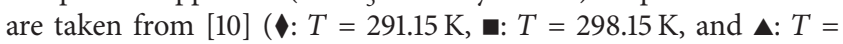
$303.15 \mathrm{~K})$.

by correlating the experimental values of surface tension of binary electrolyte solution in single temperature. For other temperatures and ternary systems, competitive adsorption model could predict the surface tension of aqueous solution. The agreement between experimental and calculated values

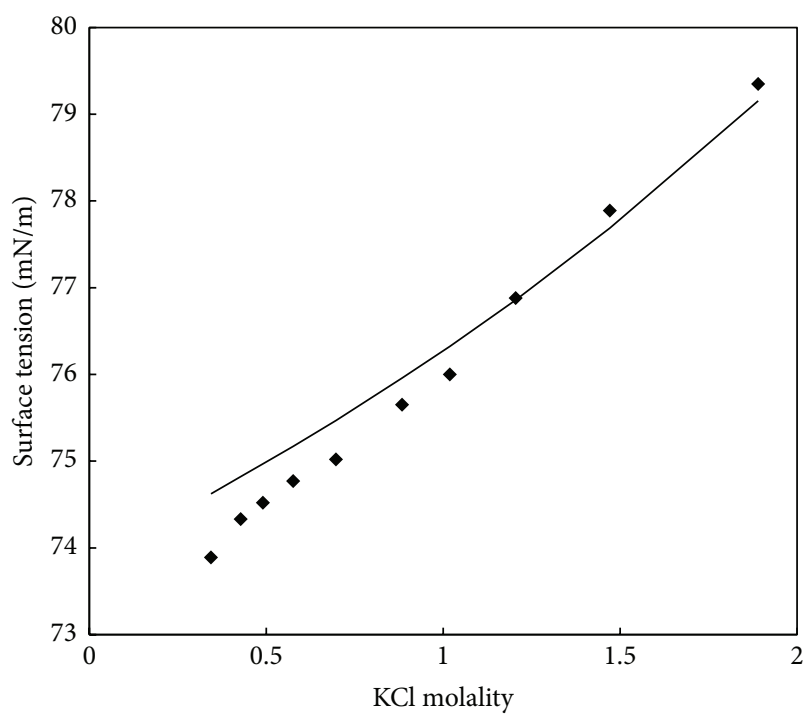

FIGURE 10: Prediction of surface tension of $\mathrm{KBr}$-KCl-water ternary system using the competitive adsorption model at $291.15 \mathrm{~K}(\mathrm{KBr}$ molality/KCl molality =1). Experimental data are taken from [10].

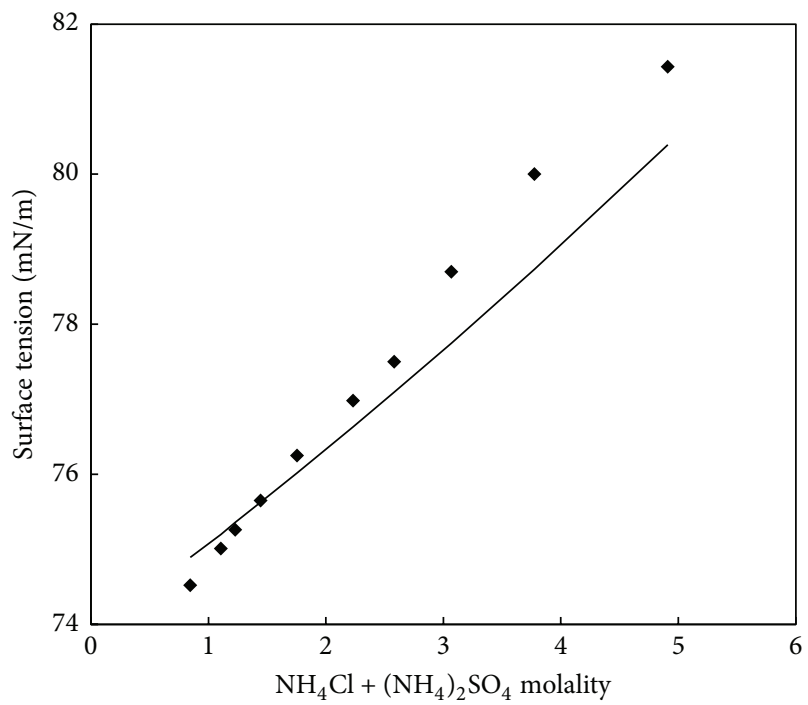

FIGure 11: Prediction of surface tension of $\mathrm{NH}_{4} \mathrm{Cl}-\left(\mathrm{NH}_{4}\right)_{2} \mathrm{SO}_{4}$ water ternary system using the competitive adsorption model at $291.15 \mathrm{~K}\left(\mathrm{NH}_{4} \mathrm{Cl}\right.$ molality/ $\left(\mathrm{NH}_{4}\right)_{2} \mathrm{SO}_{4}$ molality $\left.=1.5\right)$. Experimental data are taken from [10].

of the competitive adsorption model could introduce this new model as effective one.

\section{Conflict of Interests}

The authors declare that there is no conflict of interests regarding the publication of this paper. 
TABLE 1: The optimized values for adjustable parameters $\left(K^{*}, K\right)$ of competitive adsorption model. Experimental data are from [10].

\begin{tabular}{|c|c|c|c|c|c|}
\hline System & $T\left({ }^{\circ} \mathrm{C}\right)$ & $N_{p}$ & $K^{*}$ & K & $\mathrm{AAD} \%$ \\
\hline $\mathrm{AgNO}_{3}$ & 20 & 4 & $6.99 \times 10^{-2}$ & $6.16 \times 10^{14}$ & 0.23 \\
\hline $\mathrm{Al}_{2}\left(\mathrm{SO}_{4}\right)_{3}$ & 30 & 12 & $8.95 \times 10^{-1}$ & $3.93 \times 10^{22}$ & 0.46 \\
\hline $\mathrm{BaCl}_{2}$ & 30 & 5 & 0 & $4.53 \times 10^{4}$ & 0.61 \\
\hline $\mathrm{CaCl}_{2}$ & 30 & 11 & $6.60 \times 10^{-1}$ & $4.27 \times 10^{4}$ & 0.81 \\
\hline $\mathrm{CdCl}_{2}$ & 20 & 5 & $7.34 \times 10^{-1}$ & $2.19 \times 10^{1}$ & 0.08 \\
\hline $\mathrm{CdSO}_{4}$ & 20 & 2 & $7.47 \times 10^{-1}$ & $3.62 \times 10^{-2}$ & $9.15 \times 10^{-7}$ \\
\hline $\mathrm{CoCl}_{2}$ & 20 & 2 & $6.20 \times 10^{-1}$ & $7.51 \times 10^{-5}$ & $1.05 \times 10^{-4}$ \\
\hline $\mathrm{CsCl}$ & 25 & 15 & $1.30 \times 10^{-1}$ & $1.65 \times 10^{16}$ & 0.43 \\
\hline CsI & 25 & 11 & $1.91 \times 10^{-6}$ & $1.91 \times 10^{-6}$ & 0.45 \\
\hline $\mathrm{CuSO}_{4}$ & 30 & 3 & $7.83 \times 10^{-1}$ & $5.64 \times 10^{14}$ & 0.22 \\
\hline $\mathrm{HBr}$ & 18 & 2 & $1.09 \times 10^{0}$ & $1.86 \times 10^{16}$ & 0.07 \\
\hline $\mathrm{HCl}$ & 20 & 7 & $1.05 \times 10^{0}$ & $1.53 \times 10^{1}$ & 0.94 \\
\hline $\mathrm{HClO}_{4}$ & 25 & 10 & $1.06 \times 10^{0}$ & $2.86 \times 10^{14}$ & 2.13 \\
\hline $\mathrm{HNO}_{3}$ & 20 & 7 & $1.42 \times 10^{0}$ & $6.03 \times 10^{14}$ & 2.38 \\
\hline $\mathrm{KBr}$ & 20 & 5 & $2.36 \times 10^{-1}$ & $6.02 \times 10^{14}$ & 0.21 \\
\hline $\mathrm{KC}_{2} \mathrm{H}_{3} \mathrm{O}_{2}$ & 30 & 3 & $1.14 \times 10^{0}$ & $9.27 \times 10^{-2}$ & 0.40 \\
\hline KCNS & 25 & 12 & $9.36 \times 10^{-1}$ & $4.71 \times 10^{0}$ & 0.34 \\
\hline $\mathrm{KCl}$ & 20 & 10 & $1.07 \times 10^{-1}$ & $1.96 \times 10^{16}$ & 0.33 \\
\hline $\mathrm{K}_{2} \mathrm{CrO}_{4}$ & 30 & 15 & $2.49 \times 10^{-1}$ & $1.14 \times 10^{18}$ & 0.35 \\
\hline $\mathrm{K}_{3} \mathrm{Fe}(\mathrm{CN})_{6}$ & 25 & 16 & $1.91 \times 10^{-6}$ & $1.91 \times 10^{-6}$ & 0.67 \\
\hline $\mathrm{KI}$ & 25 & 12 & $1.91 \times 10^{-6}$ & $1.91 \times 10^{-6}$ & 3.17 \\
\hline $\mathrm{KNO}_{3}$ & 25 & 6 & $1.66 \times 10^{-1}$ & $2.73 \times 10^{15}$ & 0.38 \\
\hline $\mathrm{KOH}$ & 20 & 4 & $3.07 \times 10^{-1}$ & $8.46 \times 10^{15}$ & 0.35 \\
\hline $\mathrm{K}_{2} \mathrm{SO}_{4}$ & 25 & 12 & $1.91 \times 10^{-6}$ & $1.91 \times 10^{-6}$ & 0.72 \\
\hline $\mathrm{LiBr}$ & 30 & 4 & $6.40 \times 10^{-1}$ & $9.99 \times 10^{-2}$ & 0.34 \\
\hline $\mathrm{LiCl}$ & 25 & 7 & $4.70 \times 10^{-1}$ & $1.31 \times 10^{1}$ & 0.61 \\
\hline LiI & 18 & 2 & $6.54 \times 10^{-1}$ & $1.31 \times 10^{0}$ & $2.99 \times 10^{-6}$ \\
\hline $\mathrm{LiOH}$ & 20 & 4 & $1.28 \times 10^{-1}$ & $5.96 \times 10^{14}$ & 0.40 \\
\hline $\mathrm{Li}_{2} \mathrm{SO}_{4}$ & 18 & 2 & $4.36 \times 10^{-1}$ & $3.57 \times 10^{-2}$ & 0.15 \\
\hline $\mathrm{MgCl}_{2}$ & 20 & 12 & $7.28 \times 10^{-1}$ & $2.50 \times 10^{-1}$ & 1.13 \\
\hline $\mathrm{MgSO}_{4}$ & 10 & 12 & $8.31 \times 10^{-1}$ & $5.43 \times 10^{-3}$ & 0.75 \\
\hline $\mathrm{MnCl}_{2}$ & 18 & 6 & $6.44 \times 10^{-1}$ & $7.20 \times 10^{-3}$ & 0.23 \\
\hline $\mathrm{NH}_{4} \mathrm{Cl}$ & 25 & 6 & $2.90 \times 10^{-1}$ & $5.68 \times 10^{14}$ & 0.10 \\
\hline $\mathrm{NH}_{4} \mathrm{NO}_{3}$ & 20 & 9 & $5.20 \times 10^{-1}$ & $6.42 \times 10^{-2}$ & 0.32 \\
\hline$\left(\mathrm{NH}_{4}\right)_{2} \mathrm{SO}_{4}$ & 30 & 4 & $5.77 \times 10^{-1}$ & $6.08 \times 10^{0}$ & 0.48 \\
\hline $\mathrm{NaBr}$ & 20 & 4 & $4.85 \times 10^{-1}$ & $1.77 \times 10^{-2}$ & 0.21 \\
\hline $\mathrm{NaCHO}_{2}$ & 30 & 12 & $3.71 \times 10^{-1}$ & $1.86 \times 10^{16}$ & 0.29 \\
\hline $\mathrm{NaC}_{2} \mathrm{H}_{3} \mathrm{O}_{2}$ & 30 & 12 & $1.12 \times 10^{0}$ & $2.04 \times 10^{16}$ & 1.04 \\
\hline $\mathrm{NaC}_{3} \mathrm{H}_{5} \mathrm{O}_{2}$ & 30 & 12 & $1.91 \times 10^{0}$ & $1.27 \times 10^{18}$ & 0.26 \\
\hline $\mathrm{NaC}_{4} \mathrm{H}_{7} \mathrm{O}_{2}$ & 30 & 12 & $3.28 \times 10^{0}$ & $1.94 \times 10^{16}$ & 0.77 \\
\hline $\mathrm{NaCl}$ & 20 & 9 & $2.22 \times 10^{-1}$ & $2.05 \times 10^{16}$ & 0.66 \\
\hline $\mathrm{NaClO}_{3}$ & 15 & 2 & $1.38 \times 10^{0}$ & $4.31 \times 10^{-1}$ & 0.03 \\
\hline $\mathrm{NaClO}_{4}$ & 25 & 3 & $8.61 \times 10^{-1}$ & $2.16 \times 10^{16}$ & 0.17 \\
\hline $\mathrm{Na}_{2} \mathrm{CrO}_{4}$ & 30 & 4 & $4.23 \times 10^{-1}$ & $1.59 \times 10^{-2}$ & 0.27 \\
\hline $\mathrm{NaI}$ & 25 & 8 & $6.15 \times 10^{-1}$ & $9.07 \times 10^{14}$ & 0.16 \\
\hline $\mathrm{NaNO}_{3}$ & 20 & 4 & $2.59 \times 10^{-1}$ & $1.16 \times 10^{15}$ & 0.21 \\
\hline $\mathrm{NaOH}$ & 18 & 6 & $3.47 \times 10^{-1}$ & $2.46 \times 10^{-3}$ & 0.46 \\
\hline $\mathrm{Na}_{2} \mathrm{SO}_{4}$ & 30 & 3 & $1.50 \times 10^{-1}$ & $5.63 \times 10^{17}$ & 0.22 \\
\hline $\mathrm{Na}_{2} \mathrm{~S}_{2} \mathrm{O}_{3}$ & 40 & 4 & $4.48 \times 10^{-1}$ & $9.00 \times 10^{-3}$ & 0.21 \\
\hline
\end{tabular}


TABle 1: Continued.

\begin{tabular}{|c|c|c|c|c|c|}
\hline System & $T\left({ }^{\circ} \mathrm{C}\right)$ & $N_{p}$ & $K^{*}$ & $K$ & $\mathrm{AAD} \%$ \\
\hline $\mathrm{NiSO}_{4}$ & 15 & 2 & $7.14 \times 10^{-1}$ & $8.60 \times 10^{-2}$ & $1.75 \times 10^{-7}$ \\
\hline $\mathrm{Pb}\left(\mathrm{NO}_{3}\right)_{2}$ & 20 & 3 & $1.91 \times 10^{-6}$ & $1.91 \times 10^{-6}$ & 3.77 \\
\hline $\mathrm{RbCl}$ & 25 & 11 & $1.94 \times 10^{-1}$ & $9.65 \times 10^{15}$ & 0.36 \\
\hline $\mathrm{SrCl}_{2}$ & 20 & 9 & $5.95 \times 10^{-1}$ & $4.41 \times 10^{-3}$ & 0.49 \\
\hline $\mathrm{Sr}\left(\mathrm{NO}_{3}\right)_{2}$ & 18 & 8 & $3.39 \times 10^{-1}$ & $8.14 \times 10^{14}$ & 0.50 \\
\hline $\mathrm{UO}_{2} \mathrm{SO}_{4}$ & 30 & 12 & $8.70 \times 10^{-1}$ & $1.23 \times 10^{1}$ & 0.32 \\
\hline $\mathrm{Zn}\left(\mathrm{NO}_{3}\right)_{2}$ & 40 & 5 & $7.67 \times 10^{-1}$ & $1.27 \times 10^{-1}$ & 0.37 \\
\hline Overall & & 404 & & & 0.55 \\
\hline
\end{tabular}

TABLE 2: The absolute average deviation percent (AAD\%) in prediction of surface tension using the competitive adsorption model for binary systems. Experimental data are from [10].

\begin{tabular}{|c|c|c|c|c|}
\hline System & $T\left({ }^{\circ} \mathrm{C}\right)$ & Molality & $N_{p}$ & $\mathrm{AAD} \%$ \\
\hline $\mathrm{AgNO}_{3}$ & 100 & $1.03-13.16$ & 10 & 3.81 \\
\hline $\mathrm{BaCl}_{2}$ & $10-80$ & $0.01-5.96$ & 51 & 1.10 \\
\hline $\mathrm{CaCl}_{2}$ & $10-100$ & $0.1-7.37$ & 122 & 1.38 \\
\hline $\mathrm{CsCl}$ & $20-30$ & $0.06-8.88$ & 28 & 0.52 \\
\hline $\mathrm{CuSO}_{4}$ & $10-80$ & $0.33-1.11$ & 21 & 2.12 \\
\hline $\mathrm{HCl}$ & $25-90$ & $0.3-3$ & 18 & 3.82 \\
\hline $\mathrm{HClO}_{4}$ & $15-50$ & $0.51-25.92$ & 23 & 2.56 \\
\hline $\mathrm{HNO}_{3}$ & $30-80$ & $1.55-46.86$ & 66 & 3.71 \\
\hline $\mathrm{KBr}$ & $10-90$ & $0.44-5.6$ & 40 & 1.15 \\
\hline $\mathrm{KC}_{2} \mathrm{H}_{3} \mathrm{O}_{2}$ & $0-80$ & $0.5-23.78$ & 36 & 4.82 \\
\hline $\mathrm{KCl}$ & $25-80$ & $0.71-5.16$ & 56 & 1.03 \\
\hline $\mathrm{K}_{3} \mathrm{Fe}(\mathrm{CN})_{6}$ & $12.35-20.8$ & $0.29-0.62$ & 4 & 0.76 \\
\hline $\mathrm{KI}$ & $20-60$ & $0.01-0.12$ & 55 & 4.45 \\
\hline $\mathrm{KNO}_{3}$ & $18-100$ & $0.1-2.63$ & 27 & 1.28 \\
\hline $\mathrm{KOH}$ & $30-95$ & $4.77-13.28$ & 22 & 4.39 \\
\hline $\mathrm{LiBr}$ & $10-90$ & $1.28-17.27$ & 48 & 1.52 \\
\hline $\mathrm{LiCl}$ & $10-90$ & $1.19-15.73$ & 79 & 1.97 \\
\hline $\mathrm{MgCl}_{2}$ & $10-70$ & $0.55-3.5$ & 23 & 2.90 \\
\hline $\mathrm{NH}_{4} \mathrm{Cl}$ & $19-60$ & $1.02-7.21$ & 39 & 1.01 \\
\hline $\mathrm{NH}_{4} \mathrm{NO}_{3}$ & $40-95$ & $0.61-29.43$ & 29 & 1.21 \\
\hline$\left(\mathrm{NH}_{4}\right)_{2} \mathrm{SO}_{4}$ & $18-95$ & $0.7-5.61$ & 33 & 2.07 \\
\hline $\mathrm{NaBr}$ & $10-90$ & $0.0007-6.48$ & 58 & 3.14 \\
\hline $\mathrm{NaC}_{2} \mathrm{H}_{3} \mathrm{O}_{2}$ & $0-25$ & 0.50 & 6 & 0.94 \\
\hline $\mathrm{NaC}_{4} \mathrm{H}_{7} \mathrm{O}_{2}$ & $0-50$ & 0.50 & 10 & 1.63 \\
\hline $\mathrm{NaCl}$ & $10-200$ & $0.71-9.42$ & 81 & 1.73 \\
\hline $\mathrm{NaI}$ & $20-50$ & $0.33-8.81$ & 32 & 0.89 \\
\hline $\mathrm{NaNO}_{3}$ & $18-100$ & $1.02-11.77$ & 42 & 1.59 \\
\hline $\mathrm{NaOH}$ & $20-70$ & $0.49-6.25$ & 26 & 1.30 \\
\hline $\mathrm{Na}_{2} \mathrm{SO}_{4}$ & 10-193.4 & $0.2-1.24$ & 62 & 2.87 \\
\hline $\mathrm{RbCl}$ & $20-30$ & $0.11-6.93$ & 22 & 0.59 \\
\hline $\mathrm{SrCl}_{2}$ & $10-25$ & $0.48-1.92$ & 7 & 1.24 \\
\hline $\mathrm{UO}_{2} \mathrm{SO}_{4}$ & $20-75$ & $0.18-2.34$ & 48 & 0.81 \\
\hline $\mathrm{Zn}\left(\mathrm{NO}_{3}\right)_{2}$ & 21 & 2.62 & 1 & 1.10 \\
\hline Overall & & & 1215 & 1.98 \\
\hline
\end{tabular}


TABLE 3: The absolute average deviation percent (AAD\%) in prediction of surface tension using the competitive adsorption model for ternary systems. Experimental data are from [10].

\begin{tabular}{|c|c|c|c|c|c|}
\hline Ternary system & $m_{1}$ & $m_{2}$ & $T\left({ }^{\circ} \mathrm{C}\right)$ & $N_{p}$ & $\mathrm{AAD} \%$ \\
\hline $\mathrm{BaCl}_{2}-\mathrm{HCl}$ & $0.45-1.13$ & 0.10 & 25 & 3 & 0.47 \\
\hline $\mathrm{CaCl}_{2}-\mathrm{HCl}$ & $0.37-1.48$ & 0.10 & 25 & 4 & 1.92 \\
\hline LiCl-HCl & $0.55-4.88$ & 0.10 & 25 & 5 & 2.23 \\
\hline $\mathrm{SrCl}_{2}-\mathrm{HCl}$ & $0.48-1.92$ & 0.10 & 25 & 4 & 1.13 \\
\hline $\mathrm{KBr}-\mathrm{KCl}$ & $0.35-2.08$ & $0.34-1.89$ & 18 & 10 & 0.65 \\
\hline $\mathrm{KBr}-\mathrm{NaBr}$ & $0.44-3.57$ & $0.51-4.2$ & $10.1-90.8$ & 45 & 2.59 \\
\hline $\mathrm{KNO}_{3}-\mathrm{NH}_{4} \mathrm{NO}_{3}$ & $0.52-2.43$ & $0.12-19.54$ & $18-30$ & 143 & 6.93 \\
\hline $\mathrm{KNO}_{3}-\mathrm{Pb}\left(\mathrm{NO}_{3}\right)_{2}$ & $0-1$ & $0-1$ & 20 & 33 & 2.66 \\
\hline $\mathrm{KNO}_{3}-\mathrm{Sr}\left(\mathrm{NO}_{3}\right)_{2}$ & $0.23-1.3$ & $0.19-1.17$ & 18 & 10 & 0.92 \\
\hline $\mathrm{NH}_{4} \mathrm{Cl}-\left(\mathrm{NH}_{4}\right)_{2} \mathrm{SO}_{4}$ & $0.51-2.86$ & $0.33-2.04$ & 18 & 10 & 0.63 \\
\hline $\mathrm{NH}_{4} \mathrm{NO}_{3}-\mathrm{Pb}\left(\mathrm{NO}_{3}\right)_{2}$ & 0.33 & $0-0.333$ & 35 & 6 & 2.07 \\
\hline $\mathrm{NaNO}_{3}-\mathrm{Sr}\left(\mathrm{NO}_{3}\right)_{2}$ & $0.71-3.48$ & $0.25-1.17$ & 18 & 9 & 1.24 \\
\hline $\mathrm{NaClO}_{4}-\mathrm{HCl}$ & $0.5-1.34$ & 0.10 & 25 & 3 & 0.70 \\
\hline $\mathrm{KNO}_{3}-\mathrm{NH}_{4} \mathrm{Cl}$ & $0.23-1.3$ & $0.49-2.86$ & 18 & 10 & 1.06 \\
\hline $\mathrm{NH}_{4} \mathrm{Cl}-\mathrm{Sr}\left(\mathrm{NO}_{3}\right)_{2}$ & $0.51-2.86$ & $0.19-1.17$ & 18 & 10 & 0.91 \\
\hline$\left(\mathrm{NH}_{4}\right)_{2} \mathrm{SO}_{4}-\mathrm{NaNO}_{3}$ & $0.33-2.04$ & $0.56-3.47$ & 18 & 9 & 1.03 \\
\hline Average & & & & 314 & 1.70 \\
\hline
\end{tabular}

\section{References}

[1] Z. Li, Y. Li, and J. Lu, "Surface tension model for concentrated electrolyte aqueous solutions by the pitzer equation," Industrial \& Engineering Chemistry Research, vol. 38, no. 3, pp. 1133-1139, 1999.

[2] K. Ariyama, "A theory of surface tension of aqueous solutions of inorganic acids," Bulletin of the Chemical Society of Japan, vol. 12, no. 3, pp. 109-113, 1937.

[3] P. B. Lorenz, "The specific adsorption isotherms of thiocyanate and hydrogen ions at the free surface of aqueous solutions," Journal of Physical and Colloid Chemistry, vol. 54, no. 5, pp. 685690, 1950.

[4] T. F. Young and S. R. Grinstead, "The surface tensions of aqueous sulfuric acid solutions," Annals of the New York Academy of Sciences, vol. 51, pp. 765-780, 1949.

[5] V. G. Gleim and I. K. Shelomov, "Calculation of surface tension of aqueous salt systems," The Russian Journal of Applied Chemistry, vol. 30, pp. 29-35, 1957.

[6] S. Oka, "Adsorption and surface tension of strong electrolytes," Proceedings of the Physico-Mathematical Society of Japan, vol. 14, pp. 649-664, 1932.

[7] A. L. Horvath, Aqueous Electrolyte Solutions, Physical Properties, Estimation and Correlation Methods, Halsted Press, Chichester, UK, 1985.

[8] L. Onsager and N. N. T. Samaras, "The surface tension of debyehückel electrolytes," The Journal of Chemical Physics, vol. 2, no. 8, pp. 528-536, 1934.

[9] E. Schmutzer, "Ions at liquid/air and liquid/liquid interfaces," Zeitschrift für Physikalische Chemie, vol. 204, pp. 131-156, 1955.

[10] A. A. Abramzon and R. D. Gaukhberg, "Surface tension of salt solutions," Russian Journal of Applied Chemistry, vol. 66, no. 69, pp. 1428-2156, 1993 (Russian).

[11] Y. Yu, G. Gao, and Y. Li, "Surface tension for aqueous electrolyte solutions by the modified mean spherical approximation," Fluid Phase Equilibria, vol. 173, no. 1, pp. 23-28, 2000.
[12] Z. Li and B. C. Lu, "Surface tension of aqueous electrolyte solutions at high concentrations-representation and prediction," Chemical Engineering Science, vol. 56, no. 8, pp. 2879-2888, 2001.

[13] M. Sadeghi, V. Taghikhani, and C. Ghotbi, "Application of the MSA-based models in correlating the surface tension for single and mixed electrolyte solutions," Journal of Chemical Thermodynamics, vol. 41, no. 11, pp. 1264-1271, 2009.

[14] L. L. Lee, Molecular Thermodynamics of Nonideal Fluids, Butterworth Publishers, 1988.

[15] C. Ghotbi and J. H. Vera, "Extension to mixtures of two robust hard-sphere equations of state satisfying the ordered closepacked limit," The Canadian Journal of Chemical Engineering, vol. 79, no. 4, pp. 678-686, 2001.

[16] G. A. Mansoori, N. F. Carnahan, K. E. Starling, and T. W. Leland Jr., "Equilibrium thermodynamic properties of the mixture of hard spheres," The Journal of Chemical Physics, vol. 54, no. 4, pp. 1523-1526, 1971.

[17] C.-C. Chen and L. B. Evans, "Local composition model for the excess gibbs energy of aqueous electrolyte systems," AIChE Journal, vol. 32, no. 3, pp. 444-454, 1986.

[18] F. B. Sprow and J. M. Prausnitz, "Surface thermodynamics of liquid mixtures," The Canadian Journal of Chemical Engineering, vol. 45, no. 1, pp. 25-28, 1967.

[19] A. W. Adamson and A. P. Gast, Physical Chemistry of Surfaces, Wiley Interscience, New York, NY, USA, 3rd edition, 1997.

[20] I. Langmuir, "The adsorption of gases on plane surfaces of glass, mica and platinum," The Journal of the American Chemical Society, vol. 40, no. 9, pp. 1361-1403, 1918.

[21] C. Desnoyer, O. Masbernat, and C. Gourdon, "Predictive model for the calculation of interfacial tension in nonideal electrolytic systems," Journal of Colloid and Interface Science, vol. 191, no. 1, pp. 22-29, 1997. 

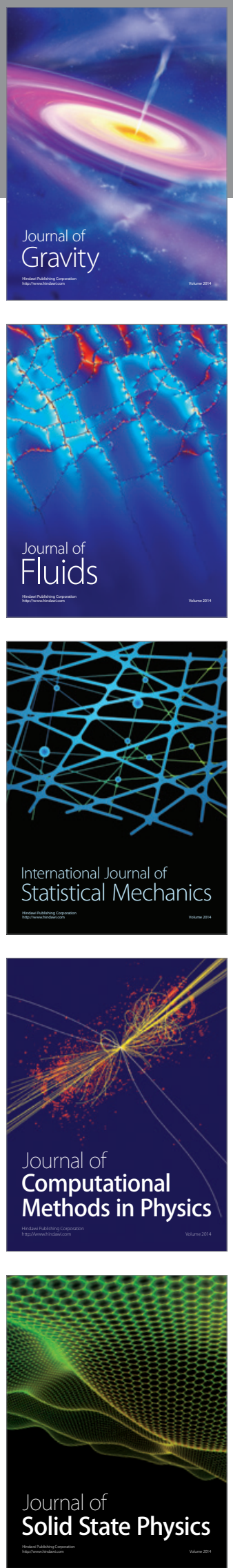

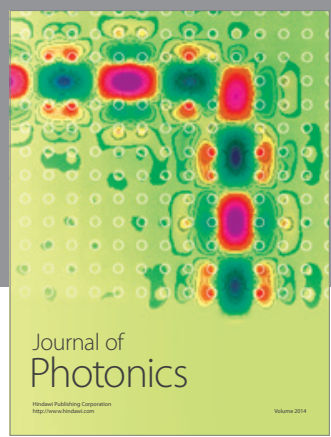

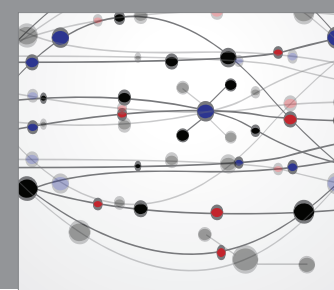

The Scientific World Journal

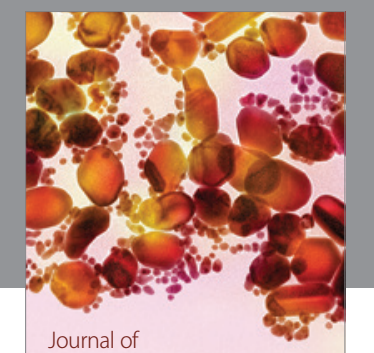

Soft Matter
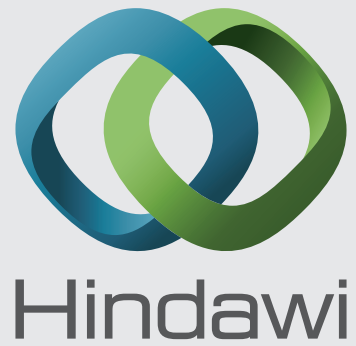

Submit your manuscripts at

http://www.hindawi.com
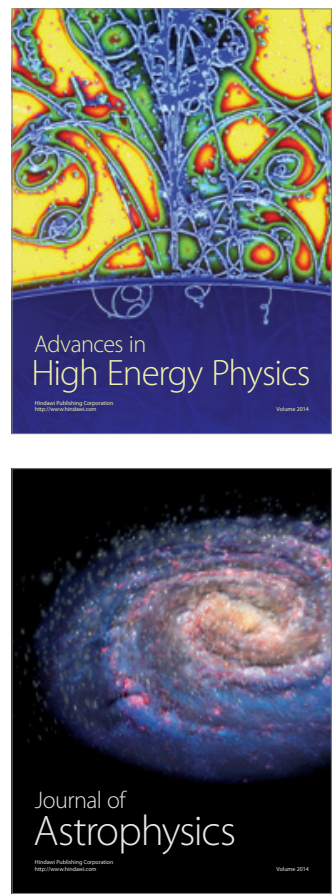
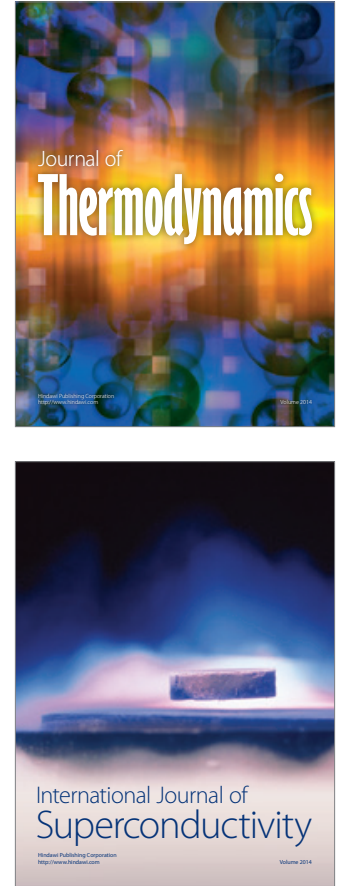
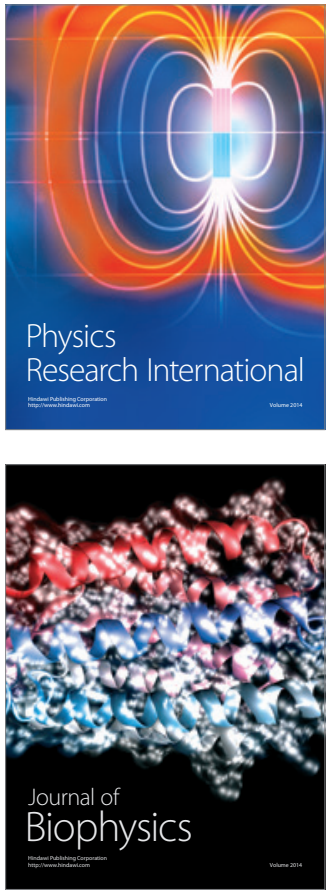
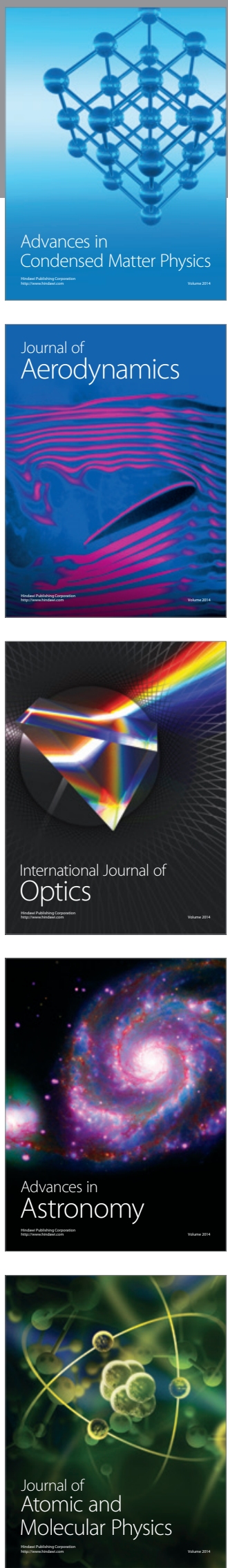